\title{
Pericardial complications of endocardial and epicardial pacing
}

JOHN DEANFIELD, ANNE JONATHAN, KIM FOX

\begin{abstract}
A patient with complete atrioventricular block was fitted with a temporary endocardial pacing wire via a right subclavian percutaneous approach. The result was initially satisfactory, but within a few days radiography for left-sided chest pain showed pneumopericardium. A permanent epicardial pacing system was therefore substituted and she remained well for three months. She was then admitted for syncope: the pacemaker was failing to capture, and radiography showed pericardial and pleural effusions. $A$ new permanent endocardial pacing system using a wedged electrode was inserted and she made an uncomplicated recovery.

Pneumopericardium complicating endocardial pacing has apparently not been reported before. Presumably the electrode had penetrated both the right ventricle and the pericardium into the adjacent lung.
\end{abstract}

\section{Introduction}

A review of 978 permanent endocardial pacemaker implantations showed that within 30 days after operation $4.6 \%$ of the devices had failed to pace. ${ }^{1}$ Most of these failures were associated with poor initial positioning of the electrode, displacement, or perforation of the myocardium. In no case was the pericardium affected. We describe a patient in whom temporary endocardial pacing resulted in a pneumopericardium, which to our knowledge has not been reported as a complication of endocardial pacing. Subsequent attempted epicardial pacing was associated with recurrent pericarditis and failure of pacing.

Division of Cardiovascular Disease, Royal Postgraduate Medical School, Hammersmith Hospital, London W12 OHS

JOHN DEANFIELD, MB, MRCP, registrar

ANNE JONATHAN, technician

KIM FOX, MD, MRCP, senior registrar

\section{Case report}

A 38-year-old Italian waitress presented in 1978 with a six-month history of fatigue and exertional dyspnoea. She was taking no medication. Examination showed no abnormality other than a regular pulse of $36 / \mathrm{min}$, and an electrocardiogram showed complete atrioventricular block with a junctional pacemaker; the atrioventricular block was confirmed by intracardiac electrophysiological study. The sinus node was functioning normally. After ventricular overdrive she had a long asystolic pause lasting five seconds, which required the pacemaker to terminate it.

We therefore decided that a temporary pacing wire should be inserted and run at a demand rate of 70 beats $/ \mathrm{min}$. The wire was inserted via a right subclavian percutaneous approach and resulted in symptomatic improvement. A few days later, however, the patient developed sharp, left-sided chest pain, aggravated by coughing and inspiration. She was found to be feverish and had a pericardial friction rub. Chest radiography showed air and fluid in the pericardial cavity (figure). The temporary pacing wire was removed and a permanent epicardial screw-in electrode pacing system inserted. A pericardial drain was left in situ. Initially a large amount of clear, sterile fluid was drained from the pericardium which gradually subsided. By the time of discharge two weeks after operation, the

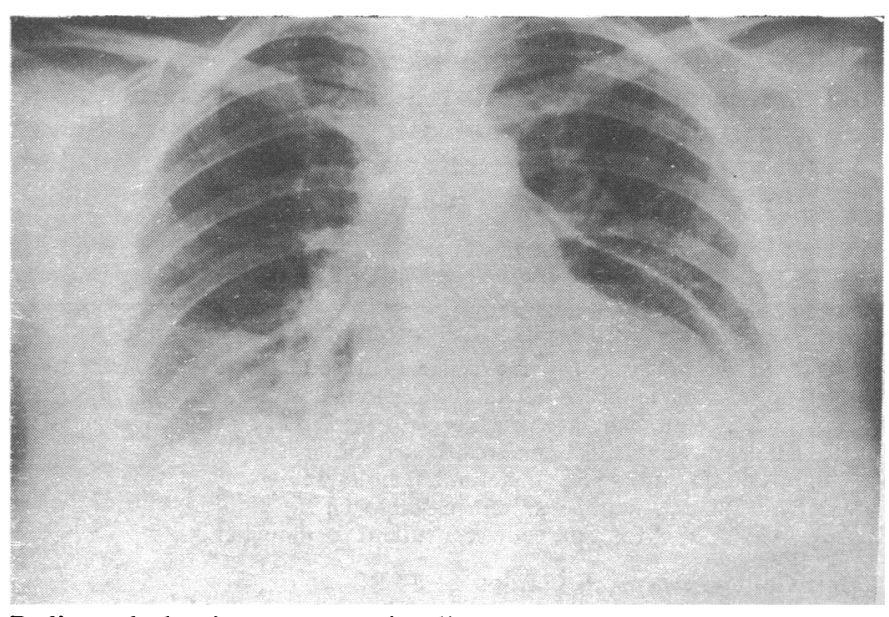

Radiograph showing pneumopericardium. 
pacemaker was working satisfactorily and there had been complete resolution of the pneumopericardium.

Three months later the patient presented with pleuritic chest pain and was admitted to hospital after a syncopal episode. She was found to be feverish and to have radiological evidence of both pericardial and pleural effusions. In addition the epicardial pacemaker was intermittently failing to capture. Postcardiotomy syndrome was diagnosed and, though aspirin resulted in rapid improvement of symptoms and of the pericardial and pleural effusions, the pacemaker continued to show intermittent failure to capture. In view of the syncopal episode a new permanent endocardial pacing system was inserted electively through a right cephalic vein cut-down, using a wedged electrode. Thereafter she made an uncomplicated recovery and was discharged home.

\section{Discussion}

In most cases effective permanent cardiac pacing may be established with a low incidence of complications. ${ }^{2-4}$ The common causes of early failure of endocardial pacing are poor positioning of the electrode initially and subsequent displacement. ${ }^{1}$ Less common but well recognised are perforation of the myocardium, fracture of the lead, infection, and failure of the generator. Temporary endocardial pacing in our patient resulted in a pneumopericardium. Presumably the electrode had penetrated not only the right ventricle but also the pericardium into the adjacent lung.
Pericarditis after epicardial pacing is a well-recognised complication. ${ }^{5}$ In our patient the early postoperative pericarditis was followed by recurrent attacks: these were thought to be due to the postcardiotomy syndrome as no infective, autoimmune, or other cause could be identified. The epicardial electrodes themselves, however, may result in focal inflammation and cause a relapsing pericarditis. ${ }^{5}$

\section{References}

1 Parsonnet V, Bilitch M, Furman S, et al. Early malfunction of transvenous pacemaker electrodes. A three centre study. Circulation 1979;60:590-6.

${ }^{2}$ Seremetis MG, de Guzman VC, Lyons WS, Peabody JW Jr. Cardiac pacemakers. Clinical experience with 289 patients. Am Heart $\mathcal{F} 1973$; $85: 739-48$.

${ }^{3}$ Davidson DM, Braak CA, Preston TA, Judge RD. Permanent ventricular pacing: effect on long term survival, congestive heart failure, and subsequent myocardial infarction and stroke. Ann Intern Med 1972; $76: 345-51$.

${ }^{4}$ Gould L, Reddy CVR, Maghazeh P, et al. Three hundred and fifty-three consecutive patients with permanent transvenous pacemakers. Pace $1980 ; 3: 452-5$.

5 Peters RW, Scheinman MM, Raskin S, Thomas AN. Unusual complications of epicardial pacemakers. Recurrent pericarditis, cardiac tamponade and pericardial constriction. Am f Cardiol 1980;45:1088-94.

(Accepted 26 fune 1981)

\section{A D TIMMIS, M B FOWLER, R J BURWOOD, P GISHEN, R VINCENT, D A CHAMBERLAIN}

\begin{abstract}
Twelve patients with acute myocardial infarction and radiological evidence of pulmonary oedema were observed in whom the left atrial pressure, measured indirectly as pulmonary artery end-diastolic pressure, was not critically increased (range $5-12 \mathrm{~mm} / \mathrm{Hg}$ with reference to sternal angle). Eight of the patients had been treated with frusemide, but only six had responded; hence in at least half of the series diuresis could not account for the anomalous finding.

Six patients with low cardiac output were given infusions to expand plasma volume. Appreciable increments in mean values for cardiac index (1.6 to $2.0 \mathrm{l} / \mathrm{min} /$ $\left.\mathrm{m}^{2}\right)$, stroke index $\left(18\right.$ to $\left.23 \mathrm{ml} / \mathrm{beat} / \mathrm{m}^{2}\right)$, mean arterial pressure (65 to $86 \mathrm{~mm} \mathrm{Hg}$ ), and pulmonary artery end-diastolic pressure ( 8 to $15 \mathrm{~mm} \mathrm{Hg}$ ) were recorded. This group, and the remaining six patients with higher cardiac output, survived to leave hospital.

Delay in radiographic clearing after a fall of left atrial pressure was a possible explanation for the rela-
\end{abstract}

Royal Sussex County Hospital, Brighton BN2 5BE

A D TIMMIS, $M B, M R C P$, cardiac registrar (present address: Department of Cardiology, Massachusetts General Hospital, Boston, Mass 02114, USA)

M B FOWLER, MB, MRCP, research registrar (present address: Department of Cardiology, King's College Hospital, London SE5)

R J BURWOOD, MD, FRCR, consultant radiologist

$R$ VINCENT, MB, MRCP, consultant cardiologist

D A CHAMBERLAIN, MD, FRCP, consultant cardiologist

King's College Hospital, London SE5 9RS

P GISHEN, MB, MRCR, consultant radiologist tively low pulmonary artery end-diastolic pressures, especially in the patients treated successfully with diuretics. Other mechanisms, such as alterations in pulmonary vascular permeability, might also have contributed to the syndrome.

Pulmonary oedema without a critical increase in the left atrial pressure is unusual in acute myocardial infarction but the therapeutic implications are important. Withdrawal of diuretics may be indicated, and in some cases expansion of plasma volume may lead to striking clinical improvement.

\section{Introduction}

Left ventricular failure in acute myocardial infarction is usually associated with an increase in left atrial pressure. As the pressure rises pulmonary venous dilatation, interstitial pulmonary oedema, and, finally, alveolar pulmonary oedema develop. ${ }^{1}$ These changes may be detected radiologically and provide a more reliable indication of left atrial pressure than do physical signs such as basal crepitations or added heart sounds. ${ }^{2}$ Thus the chest radiograph is widely used to assess diuretic requirements in acute myocardial infarction. ${ }^{3-5}$

In 1968 Nixon $^{6}$ described a patient with severe myocardial infarction and radiological signs of pulmonary oedema in whom the left atrial pressure was normal. Similar anomalous findings were later reported in other patients with infarction ${ }^{1}$ and cardiomyopathy. ${ }^{7}$ In such cases treatment with diuretics on the basis of the abnormal chest radiographs may further lower the left atrial pressure to the point at which cardiac output, by Starling's principle, is reduced. Recognising this small group of patients who have radiological evidence of pulmonary 